\title{
Synthesis of Lithocholic Acid Derivatives as Proteasome Regulators
}

\author{
Zhao Dang, ${ }^{\dagger}$ Kathy Jung, ${ }^{\dagger}$ Keduo Qian, ${ }^{\ddagger}$ Kuo-Hsiung Lee, ${ }^{\ddagger} \S$ Li Huang, ${ }^{* \dagger}$ and Chin-Ho Chen*,† \\ ${ }^{\dagger}$ Surgical Science, Department of Surgery, Duke University Medical Center, Durham, North Carolina 27710, United States \\ ${ }^{\ddagger}$ Natural Products Research Laboratories, Eshelman School of Pharmacy, University of North Carolina, Chapel Hill, North Carolina \\ 27599, United States \\ ${ }^{\S}$ Chinese Medicine Research and Development Center, China Medical University and Hospital, Taichung, Taiwan
}

\section{Supporting Information}

ABSTRACT: Accumulation of aberrant protein aggregates, such as amyloid $\beta$ peptide $(\mathrm{A} \beta)$, due to decreased proteasome activities, might contribute to the neurodegeneration in Alzheimer's disease. In this study, lithocholic acid derivatives 3 $\alpha$-O-pimeloyl-lithocholic acid methyl ester (2) and its isosteric isomer (6) were found to activate the chymotrypsin-like activity of the proteasome at an $\mathrm{EC}_{50}$ of 7.8 and $4.3 \mu \mathrm{M}$, respectively. Replacing the $\mathrm{C} 24$ methyl ester in $\mathbf{2}$ with methylamide resulted in a complete devoid of proteasome activating activity. Epimerizing the $\mathrm{C} 3$ substituent from an $\alpha$ to $\beta$ orientation

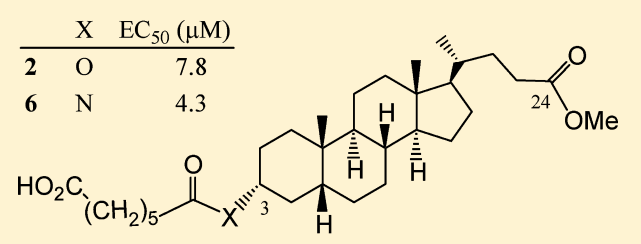

Small molecule proteasome activators transformed the activator into a proteasome inhibitor. Unlike the cellular proteasome activator PA28, proteasome activated by 2 was not inhibited by $\mathrm{A} \beta$. Furthermore, 2 potently antagonized the inhibitory effect of $\mathrm{A} \beta$ on the proteasome. In summary, compound 2 represents a novel class of small molecules that not only activates the proteasome but also antagonizes the inhibitory effect of $\mathrm{A} \beta$ on the proteasome.

KEYWORDS: proteasome activator, lithocholic acid, Alzheimer's disease, amyloid $\beta$

$\mathrm{T}$ he proteasome is the cellular machinery responsible for intracellular degradation of damaged, unwanted, or misfolded proteins. ${ }^{1,2}$ Arranged in a cylindrical structure, the proteasome (20S) contains four rings that are stacked on top of each other, with each ring composed of seven subunits. The two outer rings contain $\alpha$ subunits and do not have enzymatic activity. The two inner rings are comprised of $\beta$ subunits where the proteolytic activities reside. There are three major proteolytic activities in the $\beta$ subunits: a chymotrypsin-like $(\beta 5)$, a trypsin-like $(\beta 2)$, and a caspase-like $(\beta 1)$ activity. These proteolytic activities enable the proteasome to cleave proteins into small peptides, 8-9 amino acids in length. The $20 \mathrm{~S}$ proteasome is normally associated with $19 \mathrm{~S}$ components to form the $26 \mathrm{~S}$ proteasome. The $19 \mathrm{~S}$ components, also termed PA700, regulate the entry of proteins into the $20 \mathrm{~S}$ proteasome and activate proteasome degradation of ubiquitin-conjugated proteins. ${ }^{3}$ In addition to PA700, there are two other intracellular protein complexes, PA28 and PA200, that can activate $20 \mathrm{~S}$ proteasome using peptide substrate as models., ${ }^{4,5}$ The evolutionary conservation of multiple cellular proteasome activators underlines the importance of proteasome activators in regulating cellular function. The proteasome is involved in many essential cellular functions, such as regulation of cell cycle, cell differentiation, signal transduction pathways, antigen processing for appropriate immune responses, stress signaling, inflammatory responses, and apoptosis. ${ }^{1,2}$

The importance of the proteasome in multiple cellular functions predicates the cells for abnormalities in conditions of proteasomal dysfunction. The dysfunction and impairment of the proteasome have been linked to the aging process and neurodegenerative diseases such as Alzheimer's, Parkinson's, and Huntington's diseases. ${ }^{6}$ Proteasome dysfunction could be due to structural alteration of the proteasome during the aging or disease process. It could also result from proteasomal inhibition by misfolded proteins. For example, the amyloid $\beta$ $(\mathrm{A} \beta)$ aggregates can be degraded and cleared by the proteasome. ${ }^{7-9}$ However, higher concentrations of $\mathrm{A} \beta$ were found to inhibit the proteasome function. ${ }^{10-12}$ Inhibition of the proteasome by $\mathrm{A} \beta$ may create a vicious cycle that results in accumulation of not only more $\mathrm{A} \beta$ but also other protein aggregates, such as phosphorylated tau, which are also implicated in the pathogenesis of Alzheimer's disease (AD).$^{13-15}$ There was evidence that $\mathrm{A} \beta$-induced proteasome inhibition increased the levels of reactive oxygen species, tau tangles, and amyloid plaques, all of which are associated with $\mathrm{AD}$ pathogenesis. ${ }^{13-15}$

Enhancement of proteasome activity has been tested as a strategy to clear the unwanted proteins accumulated due to proteasome dysfunction. Overexpression of the proteasome activator PA28 was shown to enhance the survival of Huntington's disease (HD) neuronal model cells. ${ }^{16}$ Dysfunction of the ubiquitin-proteasome system was indicated in patients with $\mathrm{HD}$. The fact that overexpression of PA28 exhibited beneficial effects on the HD cell model raised the

Special Issue: Alzheimer's Disease

Received: July 13, 2012

Accepted: August 15, 2012

Published: August 15, 2012 


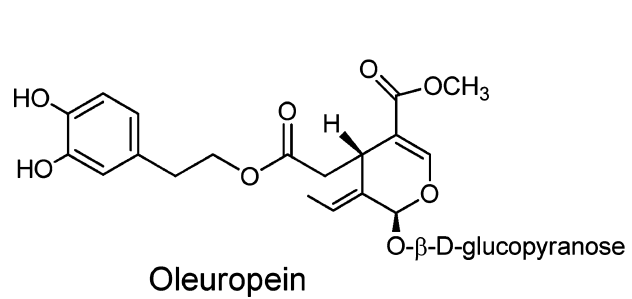<smiles>C=C(C)[C@@H]1CCC2(C(=O)O)CC[C@H]3C(CC[C@@]4(C)[C@@H]3CC[C@H]3C(C)(C)[C@@H](O)CC[C@]34C)C12</smiles>

Betulinic acid

Figure 1.

Scheme 1. Synthesis of LA Derivatives 4 and $5^{a}$<smiles>[R20]C(=O)CC[C@@H](C)[C@H]1CC[C@H]2[C@@H]3CC[C@H]4C[C@H](O)CC[C@]4(C)[C@H]3CC[C@@]21C</smiles>

$\mathrm{LA}\left(\mathrm{R}_{2}=\mathrm{H}\right)$

LA methyl ester $\left(\mathrm{R}_{2}=\mathrm{CH}_{3}\right)$

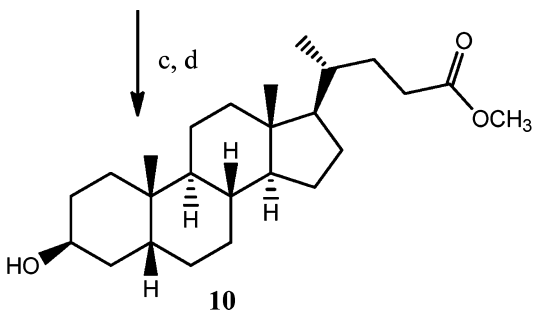

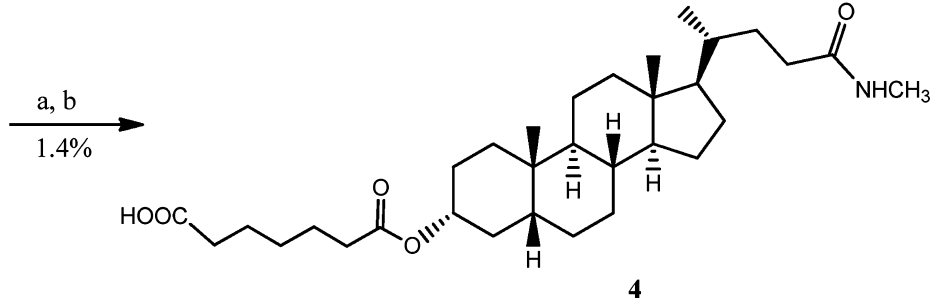

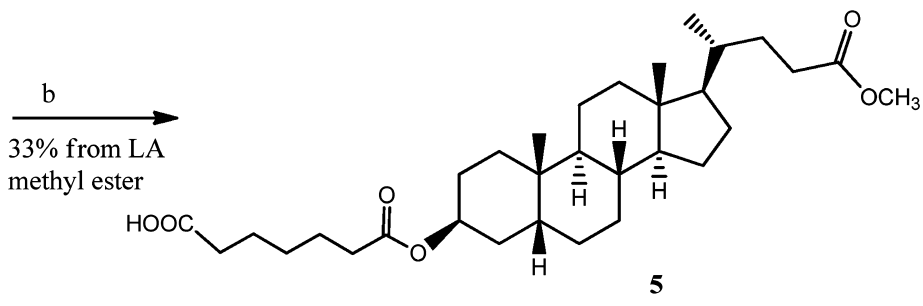

${ }^{a}$ Reagents and conditions: (a) $\mathrm{NH}_{2} \mathrm{CH}_{3} \mathrm{HCl}$, DCC. (b) Pimelic acid, DCC, DMAP, pyridine, microwave heat. (c) DEAD/Ph $3 / \mathrm{P} / \mathrm{HCOOH}$. (d) $\mathrm{KOH}, \mathrm{MeOH}$.

possibility that small molecule proteasome activators could have the potential to become useful therapeutics. However, druglike small molecules, such as betulinic acid (BA) that can activate or enhance proteasome activity, are rare and not well studied. ${ }^{17,18}$ Other proteasome activators, such as SDS at $0.05 \%$, polylysine at $1 \mathrm{mg} / \mathrm{mL}$, and peptide-based molecules at $100 \mu \mathrm{M}$, were reported. ${ }^{19}$ These compounds are either too weak or lack druglike properties to be considered as good leads. One exception is oleuropein, a polyphenol compound isolated from the leaf extract of Olea europaea (Figure 1). Oleuropein was reported to enhance proteasome activities in vitro at 0.5 $\mu \mathrm{g} / \mathrm{mL}$ and expand the proliferative life span of cultured human embryonic fibroblasts. ${ }^{20}$ In contrast to the scarcity of proteasome activator, many proteasome inhibitors have been identified from either natural products or synthetic peptide mimetics. $^{21,22}$ A peptide boronate, PS341 (Velcade), ${ }^{22,23}$ was shown to inhibit the proteasome at low nanomolar concentrations and was approved by the FDA for treating relapsed multiple myeloma. ${ }^{24}$

In light of the central role of proteasome dysfunction in aging or neurodegeneration, we were searching for small molecules that could activate the proteasome. As a result, BA was found to activate the proteasome with moderate activity (Figure 1$).{ }^{18}$ In a continued effort to synthesize more potent proteasome activators, lithocholic acid (LA) was used as a scaffold for chemical synthesis because it has a lower molecular mass and shares some structural similarity when compared to BA. Because $\mathrm{A} \beta$ was reported to inhibit the proteasome, ${ }^{10-12}$ the proteasome activators identified in this study were also tested for their ability to overcome the inhibitory effect of $A \beta$ on the proteasome. Among the LA derivatives that we synthesized with a variety of $\mathrm{C} 3, \mathrm{C} 24$, and $\mathrm{C} 3 / \mathrm{C} 24$ dual modifications, the majority of them were found to inhibit instead of activate the proteasome. ${ }^{25}$ However, the LA derivative 2 with a C3 pimeloyl side chain, which was inactive in proteasome inhibition in a previous study, was found active in proteasome activation. Thus, the current study was focused on LA derivatives with C3 pimeloyl group. The synthesis of compounds 1-3 was described previously. ${ }^{25}$ Compound 4 with the same C3 pimeloyl as 1-3 but with a methylamide side chain at C24 was synthesized by sequentially coupling LA at the C24 position with methyl amine hydrochloride and then at the $\mathrm{C} 3$ position with pimelic acid (Scheme 1). Compound 5, a diastereoisomer of 2 with a C3- $\beta$ side chain instead of $\alpha$, was synthesized from 3 - $\beta$-lithocholic acid methyl ester $(10),{ }^{26,27}$ which was converted from 3- $\alpha$ LA methylester through a Mitsunobu reaction with the treatment of formic acid-diethyl azodicarboxylate (DEAD)-triphenylphosphine followed by $\mathrm{KOH} / \mathrm{MeOH}$-catalyzed hydrolysis (Scheme 1).

To synthesize the C3 amide isosteric isomers 6 and 7, LA was oxidized with Jones reagent, followed by esterification at $\mathrm{C} 24$ with ethanol/ $\mathrm{HCl}$ to form the $\mathrm{C} 3$ ketone/C24 ethyl ester intermediate 11. Compound $\mathbf{1 1}$ was heated to reflux in formamide to give an $\alpha / \beta$ mixture of C3 formylaminosubstituted $12 \mathrm{a}$ and $\mathbf{1 2 b}$. The mixture of $12 \mathrm{a}$ and $\mathbf{1 2 b}$ can be easily separated by partially dissolving the mixture in ethyl ether or methanol, in which the $3 \alpha$-fomylamino-lithocholic acid ethyl ester (12a) remained solid as it has a much lower solubility than its $\beta$ isomer $(\mathbf{1 2 b}) .{ }^{28}$ Further treatment of the pure 12a and $\mathbf{1 2 b}$ with methanol/ $\mathrm{HCl}$ under reflux resulted in 
Scheme 2. Synthesis of LA Derivatives $6-9^{a}$

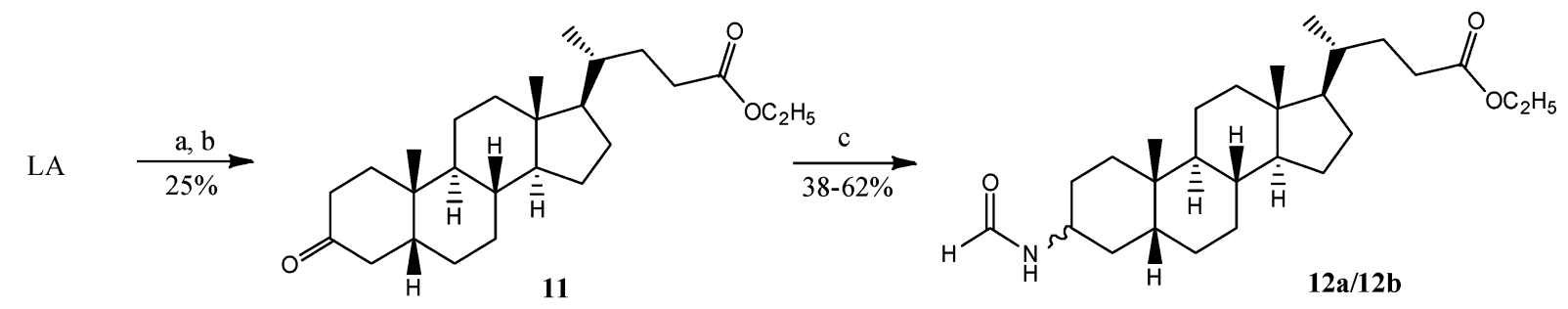

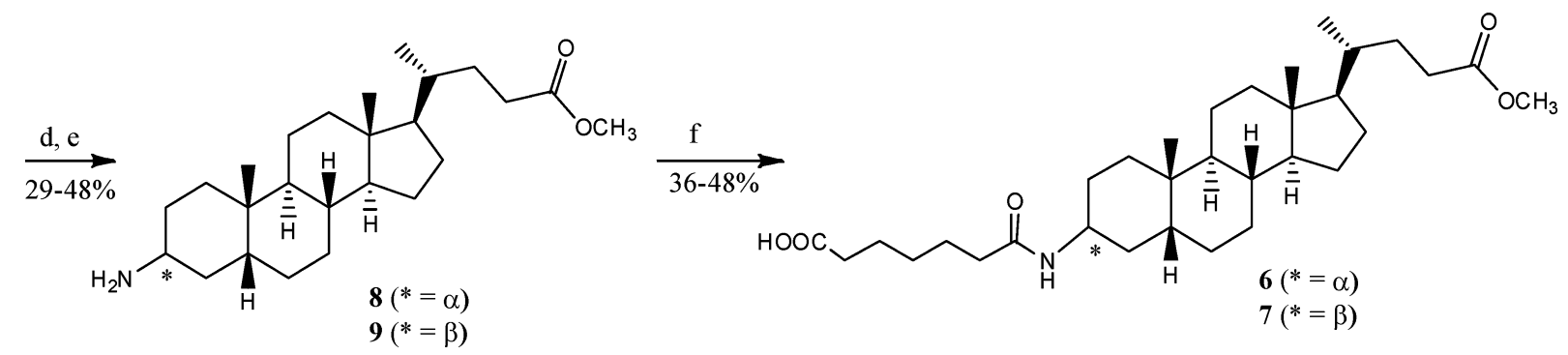

${ }^{a}$ Reagents and conditions: (a) Jones reagent, acetone. (b) EtOH, $\mathrm{HCl}$. (c) Formamide, heat. (d) $\mathrm{MeOH}$ or $\mathrm{Et}_{2} \mathrm{O}$ partial precipatation. (e) $\mathrm{MeOH} /$ $\mathrm{HCl}$, reflux. (f) Pimelic acid, DCC, DMAP, pyridine, microwave heat.

Table 1. Regulation of Proteasome Activity by LA Derivatives

\begin{tabular}{|c|c|c|c|c|}
\hline Compounds & $\mathbf{R}_{\mathbf{1}}$ & $\mathbf{R}_{\mathbf{2}}$ & ${ }^{a, c} \mathbf{E C}_{\mathbf{5 0}}(\mu \mathrm{M})$ & ${ }^{b, c} \mathbf{I} \mathbf{C}_{\mathbf{5 0}}(\mu \mathrm{M})$ \\
\hline Oleuropein & & & - & - \\
\hline Lithocholic acid & $\mathrm{H}$ & $\mathrm{OH}$ & - & Inhibition $(>10)$ \\
\hline 1 & $\mathrm{HO}_{2} \mathrm{C}^{-}\left(\mathrm{CH}_{2}\right)_{5}-\mathrm{r}^{\mathrm{O}} "$ & $\mathrm{OH}$ & $>15$ & - \\
\hline 2 & $\mathrm{HO}_{2} \mathrm{C}-\left(\mathrm{CH}_{2}\right) \mathrm{T}_{0} \mathrm{O}^{\mathrm{O}}$ & $\mathrm{OCH}_{3}$ & $\begin{array}{r}7.8 \pm 2.3 \\
{ }^{d} 8.6 \pm 2.5 \\
{ }^{e} 11.0 \pm 3.3\end{array}$ & - \\
\hline 3 & $\left.\mathrm{HO}_{2} \mathrm{C}-\left(\mathrm{CH}_{2}\right)_{5}\right]_{0}{ }^{\mathrm{O}} "$ & $\mathrm{OC}_{2} \mathrm{H}_{5}$ & $>15$ & - \\
\hline 4 & $\mathrm{HO}_{2} \mathrm{C}-\left(\mathrm{CH}_{2}\right)_{5}-\mathrm{Y}^{\mathrm{O}} "$ & $\mathrm{NHCH}_{3}$ & - & - \\
\hline 5 & $\mathrm{HO}_{2} \mathrm{C}-\left(\mathrm{CH}_{2}\right) \mathrm{T}_{\mathrm{S}} \mathrm{T}^{\mathrm{O}}$ & $\mathrm{OCH}_{3}$ & - & $3.1 \pm 0.91$ \\
\hline 6 & $\mathrm{HO}_{2} \mathrm{C}-\left(\mathrm{CH}_{2}\right){ }_{0} \gamma_{0} \mathrm{~N}^{\mathrm{N}}$ & $\mathrm{OCH}_{3}$ & $4.3 \pm 1.5$ & - \\
\hline 7 & $\mathrm{HO}_{2} \mathrm{C}-\left(\mathrm{CH}_{2}\right) T_{0} \times{ }_{0}^{\mathrm{N}}$ & $\mathrm{OCH}_{3}$ & - & $2.6 \pm 0.82$ \\
\hline 8 & $\mathrm{H}_{2} \mathrm{~N}^{\prime \prime \prime \prime}$ & $\mathrm{OCH}_{3}$ & $6.7 \pm 2.3$ & - \\
\hline 9 & $\mathrm{H}_{2} \mathrm{~N}^{-}$ & $\mathrm{OCH}_{3}$ & - & $5.7 \pm 1.8$ \\
\hline
\end{tabular}

${ }^{a} \mathrm{EC}_{50}$ is the median effective activation concentration for chymotrypsin-like activity of human $20 \mathrm{~S}$ proteasome. $\mathrm{EC}_{50}$ was obtained using the nonlinear regression program of CalcuSyn. ${ }^{b} \mathrm{IC}_{50}$ is the concentration that inhibited the chymotrypsin-like proteasome activity by $50 \%$ in the presence of PA28. ${ }^{c}$ The $\mathrm{EC}_{50}$ and $\mathrm{IC}_{50}$ in the table represent the mean $\pm \mathrm{SD}$ of three independent experiments. ${ }^{d} \mathrm{EC}_{50}$ for activation of trypsin-like activity. ${ }^{e} \mathrm{EC}_{50}$ for activation of caspase-like activity. -, Inactive.

corresponding C3- $\alpha$ (8) and C3- $\beta$ (9) aminolithocholic acid methyl ester, respectively. The configurations of the $\mathrm{C} 3$ isomers were confirmed by identifying 9 as the same compound in literature obtained by Mitsunobu conversion of the 3- $\alpha$ lithocholic acid methyl ester to 3 - $\beta$-amino-lithocholic acid methyl ester. ${ }^{29}$ Compounds 6 and 7 were subsequently obtained by coupling pimelic acid to 8 or 9 , respectively (Scheme 2).

The effect of the compounds on the proteasome was determined by incubating the compounds with the $20 \mathrm{~S}$ proteasome and fluorogenic peptide substrates in the presence (for inhibitor) or absence (for activator) of PA28. Cleavage of the substrates by the proteasome resulted in emission of fluorescence, which was recorded and used for calculating the potency of the compounds. The detailed methodology is described in the Supporting Information and in previous reports. $^{18,25}$ The activating or inhibitory effects of the LA derivatives with $\mathrm{C} 3$ pimeloyl substituent on the chymotrypsinlike activity of the proteasome are summarized in Table 1. Oleuropein, a natural product previously reported to have proteasome activation activity, is also included in the study; ${ }^{20}$ however, it did not show any significant activity in activating 
the chymotrypsin-like activity of the proteasome under our assay conditions. Unmodified LA did not activate the proteasome and is a weak proteasome inhibitor.

In our previous study, we found that certain C3-modified LA derivatives inhibited proteasome activity with moderate potency, but none of the C24-esterified LA derivatives inhibited the proteasome including compounds $1-3 .{ }^{25}$ However, further study revealed that compound 2 with $\mathrm{C} 3$ pimeloyl group and C24 methyl ester can activate the proteolysis activity of the proteasome (Table 1). The concentration required for 2 to activate the chymotrypsin-like activity of the proteasome to $50 \%$ of its maximum level $\left(\mathrm{EC}_{50}\right)$ was $7.8 \mu \mathrm{M}$. Compound 2 also activated the trypsin-like and caspase-like activities of the proteasome at 8.6 and $11 \mu \mathrm{M}$, respectively. The proteasome activation activity of $\mathbf{2}$ was quite sensitive to minor changes in the $\mathrm{C} 24$ side chain. A change from $\mathrm{CH}_{3} \mathrm{O}-$ to $\mathrm{C}_{2} \mathrm{H}_{5} \mathrm{O}-$ or $\mathrm{CH}_{3} \mathrm{NH}-$ at $\mathrm{C} 24$ as seen in compounds 3 and 4 completely abrogated the proteasome activation activity. Modification of the C3 side chain could also affect the potency of the LA derivatives. An isosteric change of the $\mathrm{C} 3$ ester linkage into an amide linkage resulted in compound $\mathbf{6}$ and increased the proteasome activation activity by approximately 2 -fold. Compound 6 activated the chymotrypsin-like activity to $50 \%$ maximal at $4.3 \mu \mathrm{M}$.

One particularly interesting finding is that the stereochemistry of the $\mathrm{C} 3$ side chain of compounds 2,6 , and 8 dictated whether the compound was an activator or inhibitor. The C3 side chains of compounds 2,6 , and 8 have an $\alpha$ orientation, whereas their corresponding stereoisomers 5,7 , and 9 have a $\beta$ orientation. In contrast to the $\alpha$ stereoisomers discussed above, 5, 7, and 9 did not activate the proteasome. Instead, these three compounds all inhibited the proteasome (Table 1). The stereospecific proteasome regulatory activity suggests that these three compounds specifically interact with a critical motif on the proteasome to modulate its proteolytic activity.

To determine if LA derivatives could overcome the inhibitory effect of $\mathrm{A} \beta$ on the proteasome, we designed and carried out the experiments using $\mathrm{A} \beta_{1-42}$, the likely pathogenic form of $\mathrm{A} \beta .^{30}$ As shown in Figure $2 \mathrm{a}, \mathrm{A} \beta_{1-42}$ inhibited the proteasome in a dose-dependent manner. The slope of each line in the figure represents the reaction rate and is positively correlated with the activity of the proteasome. The top line (line 1) in the figure represents the proteasome activity without the presence of $\mathrm{A} \beta_{1-42}$. Line 4 in Figure $2 \mathrm{a}$ shows that $\mathrm{A} \beta_{1-42}$ inhibited the proteasome by greater than $90 \%$ at $10 \mu \mathrm{g} / \mathrm{mL}$. These results confirmed that $\mathrm{A} \beta_{1-42}$ is a proteasome inhibitor, which allowed us to further test our hypothesis as to whether a small molecule proteasome activator, such as $\mathbf{2}$, can antagonize the inhibitory effect of $\mathrm{A} \beta_{1-42}$ on the proteasome. $\mathrm{A} \beta_{1-42}$ was used at a concentration of $10 \mu \mathrm{g} / \mathrm{mL}$ in further experiments to study the relationship between 2 and $A \beta_{1-42}$ in terms of proteasome activity.

In evaluating whether compound $\mathbf{2}$ could activate the proteasome in the presence of $\mathrm{A} \beta_{1-42}, 2$ was used at $18 \mu \mathrm{M}$, a concentration at which it potently activate the proteasome. Compound 2 at $18 \mu \mathrm{M}$ potently activated the chymotrypsinlike activity of the proteasome (line 2, Figure $2 b$ ). The effect of $\mathrm{A} \beta_{1-42}$ on compound 2 -activated proteasome was determined in the presence of various concentrations of $\mathrm{A} \beta_{1-42}$. At concentrations ranging from 1.1 to $30 \mu \mathrm{g} / \mathrm{mL}, \mathrm{A} \beta_{1-42}$ did not inhibit 2-activated chymotrypsin-like activity of the proteasome (Figure $2 \mathrm{~b}$ ). In contrast, at $10 \mu \mathrm{g} / \mathrm{mL}, \mathrm{A} \beta_{1-42}$ inhibited PA28-
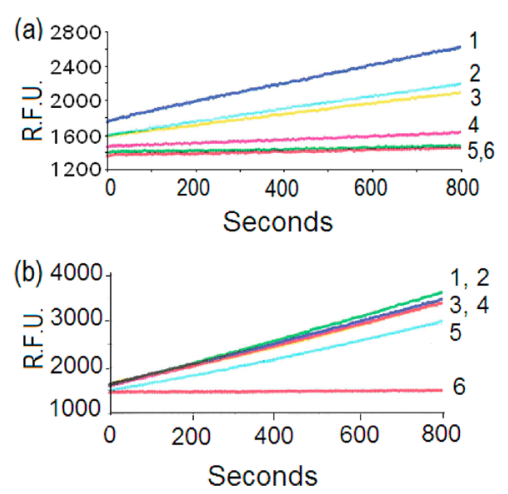

Figure 2. $\mathrm{A} \beta_{1-42}$ inhibited PA28-activated but not compound 2activated proteasome. (a) Inhibition of PA28-activated proteasome. The cellular proteasome activator PA28 $(1.8 \mu \mathrm{g} / \mathrm{mL})$ was used to activate the proteasome (line 1). $\mathrm{A} \beta_{1-42}$ at various concentrations was added to inhibit the PA28-activated proteasome activity. The concentrations of $\mathrm{A} \beta_{1-42}$ used in the assay were 1.1 (line 2), 3.3 (line 3), 10 (line 4), and $30 \mu \mathrm{g} / \mathrm{mL}$ (line 5). Line 6 was background control (the proteasome and the substrate Suc-LLVY-AMC). R.F.U., relative fluorescence units. (b) A $\beta$ did not inhibit compound 2activated proteasome. Compound $2(18 \mu \mathrm{M})$ was used to activate the proteasome (line 2). $\mathrm{A} \beta_{1-42}$ at various concentrations was added to inhibit the compound $\mathbf{2}$-activated proteasome activity. The concentrations of $\mathrm{A} \beta_{1-42}$ used in the assay were 30 (line 1), 10 (line 3), 3.3 (line 4), and $1.1 \mu \mathrm{g} / \mathrm{mL}$ (line 5). Line 6 was the background control.

activated proteasome activity by more than $90 \%$ (Figure 2a). These results indicated that compound 2 could activate the proteasome and that $\mathrm{A} \beta_{1-42}$ was ineffective at inhibiting compound 2 -activated proteasome.

The results shown in Figure $2 \mathrm{~b}$ were derived from assays in the absence of the cellular proteasome activator PA28. To determine whether compound $\mathbf{2}$ could reverse the inhibitory effect of $\mathrm{A} \beta_{1-42}$ on the PA28-activated proteasome, the PA28activated proteasomal activity was tested in the presence of $\mathrm{A} \beta_{1-42}$ and various concentrations of compound 2 . The results indicated that PA28-activated proteasome activity was completely inhibited by $\mathrm{A} \beta_{1-42}$ at $10 \mu \mathrm{g} / \mathrm{mL}$ (line 5, Figure 3). The

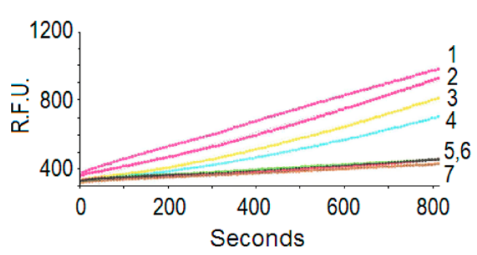

Figure 3. Compound 2 antagonized the inhibitory effect of $A \beta_{1-42}$ on PA28-activated proteasome. The cellular proteasome activator PA28 $(1.8 \mu \mathrm{g} / \mathrm{mL})$ was used to activate the proteasome (line 1$). \mathrm{A} \beta_{1-42}(10$ $\mu \mathrm{g} / \mathrm{mL}$ ) was added to inhibit the PA28-activated proteasome activity (line 5). Compound 2 at various concentrations was added to antagonize the inhibitory effect of $\mathrm{A} \beta_{1-42}$ on the proteasome. The concentrations of 2 used in the assay were 56 (line 2), 28 (line 3), and $14 \mu \mathrm{M}$ (line 4). Lines 6 and 7 were background (the proteasome and the substrate Suc-LLVY-AMC) and solvent control, respectively.

addition of compound 2 antagonized the $\mathrm{A} \beta_{1-42}$-mediated proteasome inhibition in a dose-dependent manner (line 2-4, Figure 3 ). Compound 2 was able to reverse the inhibitory activity of $\mathrm{A} \beta_{1-42}$ by over $50 \%$ at $14 \mu \mathrm{M}$ (line 4 , Figure 3 ). This result strongly suggested that 2 could antagonize the inhibitory effect of $\mathrm{A} \beta_{1-42}$ on PA28-activated proteasome. 
In this study, we have successfully identified several novel LA derivatives that can activate the proteasome and demonstrated that one of the most active compound (2) could activate the proteasome in the presence of $\mathrm{A} \beta_{1-42}$ and antagonize the inhibitory effect of $\mathrm{A} \beta_{1-42}$ on the proteasome. Small molecule proteasome activators are rare. BA and oleuropein are two small molecules that have been found to activate the proteasome. ${ }^{18,20}$ Oleuropein was previously described to activate the proteasome to approximately 1.5 -fold over background proteasome activity in the absence of cellular proteasome activators. ${ }^{20}$ However, this compound did not activate the proteasome under our experimental conditions. Our experimental data suggested that LA has the potential to serve as an ideal scaffold to derive novel proteasome activators (Table 1). LA exhibits an unusual toxicity profile in that it is safe for humans but toxic to small animals and other primates. ${ }^{31}$

The results shown in Figure $2 \mathrm{~b}$ indicated that $\mathrm{A} \beta_{1-42}$ was unable to inhibit the proteasome in the presence of the proteasome activator $\mathbf{2}$. Compound $\mathbf{2}$ may have activated the proteasome by a different mechanism from the cellular proteasome activator, PA28. The fact that PA28 and 2 act by different mechanisms of action, such as binding to distinct allosteric sites on the proteasome, might explain why PA28activated proteasome was sensitive to $\mathrm{A} \beta_{1-42}$ inhibition, whereas compound 2 -activated proteasome was not. Recently, a study has shown that methylene blue can slightly enhance proteasome activity, which might correlate with a reduction of $\mathrm{A} \beta_{1-42}$ in the brains of an $\mathrm{AD}$ mouse model. ${ }^{32}$ However, it is not clear whether methylene blue can directly activate the proteasome or antagonize $\mathrm{A} \beta_{1-42}$. Thus, this study is the first to show that a proteasome activator can directly counter the inhibitory effect of $\mathrm{A} \beta_{1-42}$ on the proteasome. The ability of 2 to antagonize $\mathrm{A} \beta_{1-42}$ was further demonstrated by the fact that 2 could completely reverse the inhibitory effect of $\mathrm{A} \beta_{1-42}$ on PA28-activated proteasome (Figure 3). This result suggested that compound $\mathbf{2}$ has the potential to rescue the proteasome from the inhibitory effects of $\mathrm{A} \beta_{1-42}$ by recovering the clearance function of the proteasome. The novel proteasome activators discovered in this study may become useful tools to study how the proteasome plays a role in so many vital cellular processes, such as cell cycle regulation and apoptosis. Future studies will include determining the effectiveness of these compounds in intracellular milieus.

\section{ASSOCIATED CONTENT}

\section{S Supporting Information}

Methods of organic synthesis, proteasome assays, and spectroscopic data of synthesized compounds. This material is available free of charge via the Internet at http://pubs.acs.org.

\section{AUTHOR INFORMATION}

\section{Corresponding Author}

*Tel: 919-684-2952. Fax: 919-684-3878. E-mail: li.huang@ duke.edu (L.H.). Tel: 919-684-3819. Fax: 919-684-3878. Email: chc@duke.edu (C.H.C.).

\section{Funding}

This work was supported by the National Institute of General Medical Sciences (NIGMS) Grant AI-84337 awarded to C.H.C. and the Alzheimer's Drug Discovery Foundation (ADDF) Grant 20110802 to L.H.

\section{Notes}

The authors declare no competing financial interest.

\section{ABBREVIATIONS}

LA, lithocholic acid; DCC, $N, N^{\prime}$-dicyclohexylcarbodiimide; DMAP, 4-(dimethylamino)pyridine; DEAD, diethyl azodicarboxylate

\section{REFERENCES}

(1) Voges, D.; Zwickl, P.; Baumeister, W. The 26S proteasome: A molecular machine designed for controlled proteolysis. Annu. Rev. Biochem. 1999, 68, 1015-1068.

(2) Rechsteiner, M.; Hill, C. P. Mobilizing the proteolytic machine: Cell biological roles of proteasome activators and inhibitors. Trends Cell Biol. 2005, 15, 27-33.

(3) DeMartino, G. N.; Slaughter, C. A. The proteasome, a novel protease regulated by multiple mechanisms. J. Biol. Chem. 1999, 274, 22123-22126.

(4) Rechsteiner, M.; Realini, C.; Ustrell, V. The proteasome activator 11 S REG (PA28) and class I antigen presentation. Biochem. J. 2000, $345,1-15$.

(5) Ustrell, V.; Hoffman, L.; Pratt, G.; Rechsteiner, M. PA200, a nuclear proteasome activator involved in DNA repair. $E M B O$ J. 2002, $21,3516-3525$.

(6) Dennissen, F. J.; Kholod, N.; van Leeuwen, F. W. The ubiquitin proteasome system in neurodegenerative diseases: Culprit, accomplice or victim? Prog. Neurobiol. 2012, 96, 190-207.

(7) Marambaud, P.; Zhao, H.; Davies, P. Resveratrol promotes clearance of Alzheimer's disease amyloid-beta peptides. J. Biol. Chem. 2005, 280, 37377-37382.

(8) Burns, M. P.; Zhang, L.; Rebeck, G. W.; Querfurth, H. W.; Moussa, C. E. Parkin promotes intracellular Abeta1-42 clearance. Hum. Mol. Genet. 2009, 18, 3206-3216.

(9) Zhao, X.; Yang, J. Amyloid- $\beta$ peptide is a substrate of the human $20 S$ proteasome. ACS Chem. Neurosci. 2010, 1, 655-660.

(10) Tseng, B. P.; Green, K. N.; Chan, J. L.; Blurton-Jones, M.; LaFerla., F. M. A-beta inhibits the proteasome and enhances amyloid and tau accumulation. Neurobiol. Aging 2008, 29, 1607-1618.

(11) Gregori, L.; Hainfeld, J. F.; Simon, M. N.; Goldgaber, D. Binding of amyloid beta protein to the $20 \mathrm{~S}$ proteasome. J. Biol. Chem. 1997, 272, 58-62.

(12) Gregori, L.; Fuchs, C.; Figueiredo-Pereira, M. E.; Van Nostrand, W. E.; Goldgaber, D. Amyloid beta-protein inhibits ubiquitindependent protein degradation in vitro. J. Biol. Chem. 1995, 270, 19702-19708.

(13) Kosik, K. S.; Joachim, C. L.; Selkoe, D. J. Microtubule-associated protein tau $(\tau)$ is a major antigenic component of paired helical filaments in Alzheimer disease. Proc. Natl. Acad. Sci. U.S.A. 1986, 83, 4044-4048.

(14) LaFerla, F. M.; Green, K. N.; Oddo, S. Intracellular amyloid-beta in Alzheimer's disease. Nat. Rev. Neurosci. 2007, 8, 499-509.

(15) Grune, T.; Botzen, D.; Engels, M.; Voss, P.; Kaiser, B.; Jung, T.; Grimm, S.; Ermak, G.; Davies, K. J. Tau protein degradation is catalyzed by the ATP/ubiquitin-independent $20 \mathrm{~S}$ proteasome under normal cell conditions. Arch. Biochem. Biophys. 2010, 500, 181-188.

(16) Seo, H.; Sonntag, K. C.; Kim, W.; Cattaneo, E.; Isacson, O. Proteasome activator enhances survival of Huntington's disease neuronal model cells. PLoS ONE 2007, 2, e238.

(17) Huang, L.; Chen, C. H. Proteasome regulators: Activators and inhibitors. Curr. Med. Chem. 2009, 16, 931-939.

(18) Huang, L.; Ho, P.; Chen, C. H. Activation and inhibition of proteasomes by betulinic acid and its derivatives. FEBS Lett. 2007, 581, 2955-2959.

(19) Tanaka, K.; Ii, K.; Ichihara, A.; Waxman, L.; Goldberg, A. L. A high molecular weight protease in the cytosol of rat liver. I. Purification, enzymological properties, and tissue distribution. J. Biol. Chem. 1986, 261, 15197-15203.

(20) Katsiki, M.; Chondrogianni, N.; Chinou, I.; Rivett, A. J.; Gonos, E. S. The olive constituent oleuropein exhibits proteasome stimulatory properties in vitro and confers life span extension of human embryonic fibroblasts. Rejuvenation Res. 2007, 10, 157-172. 
(21) Kessler, B. M.; Tortorella, D.; Altun, M.; Kisselev, A. F.; Fiebiger, E.; Hekking, B. G.; Ploegh, H. L.; Overkleeft, H. S. Extended peptide-based inhibitors efficiently target the proteasome and reveal overlapping specificities of the catalytic $\beta$-subunits. Chem. Biol. 2001, 8, 913-929.

(22) Kisselev, A. F.; Goldberg, A. L. Proteasome inhibitors: From research tools to drug candidates. Chem. Biol. 2001, 8, 739-758.

(23) Adams, J.; Behnke, M.; Chen, S.; Cruickshank, A. A.; Dick, L. R.; Grenier, L.; Klunder, J. M.; Ma, Y. T.; Plamondon, L.; Stein, R. L. Potent and selective inhibitors of the proteasome: Dipeptidyl boronic acids. Bioorg. Med. Chem. Lett. 1998, 8, 333-338.

(24) Mohty, B.; El-Cheikh, J.; Yakoub-Agha, I.; Avet-Loiseau, H.; Moreau, P.; Mohty, M. Treatment strategies in relapsed and refractory multiple myeloma: A focus on drug sequencing and 'retreatment' approaches in the era of novel agents. Leukemia 2012, 26, 73-85.

(25) Dang, Z.; Lin, A.; Ho, P.; Soroka, D.; Lee, K. H.; Huang, L.; Chen, C. H. Synthesis and proteasome inhibition of lithocholic acid derivatives. Bioorg. Med. Chem. Lett. 2011, 21, 1926-1929.

(26) Nahar, L.; Turner, A. B. Synthesis of ester-linked lithocholic acid dimmers. Steroids 2003, 68, 1157-1161.

(27) Mitsunobu, O. The use of diethyl azodicarboxylate and triphenylphosphine in synthesis and transformation of natural products. Synthesis 1981, 1, 1-28.

(28) Bellini, A. M.; Mencini, E.; Quaglio, M. P.; Guarneri, N.; Fini, A. Antimicrobial activity of basic cholane derivatives. X. Synthesis of 3alpha- and 3beta-amino-5beta-cholan-24-oic acids. Steroids 1991, 56, 395-398.

(29) Anelli, P. L.; Lattuada, L.; Uggeri, F. One-pot mitsunobustaudinger preparation of 3-aminocholan-24-oic acid esters from 3hydroxycholan-24-oic acid esters. Synth. Commun. 1998, 28, 109-117.

(30) Klein, W. L.; Stine, W. B.; Teplow, D. B. Small assemblies of unmodified amyloid $\beta$-protein are the proximate neurotoxin in Alzheimer's disease. Neurobiol. Aging 2004, 25, 569-580.

(31) Hofmann, A. F. Detoxification of lithocholic acid, a toxic bile acid: Relevance to drug hepatotoxicity. Drug Metab. Rev. 2004, 36, $703-722$.

(32) Medina, D. X.; Caccamo, A.; Oddo, S. Methylene blue reduces abeta levels and rescues early cognitive deficit by increasing proteasome activity. Brain Pathol. 2011, 21, 140-149. 